\title{
Multiple roles for U6 snRNA in the splicing pathway
}

\author{
Hiten D. Madhani, ${ }^{1}$ Rémy Bordonné, ${ }^{1}$ and Christine Guthrie \\ Department of Biochemistry and Biophysics, University of California, San Francisco, California 94143 USA
}

U6 is the most highly conserved of the five spliceosomal RNAs. It is associated with U4 by an extensive basepairing interaction, which is disrupted immediately prior to the first nucleolytic step of splicing. It has been proposed that this event activates catalysis by unmasking U6. Using a combination of doped synthesis and site-directed mutagenesis to generate point mutations in U6, we have now identified 12 positions, in three domains, at which single nucleotide substitutions or deletions result in lethal or temperature-sensitive phenotypes. Biochemical analysis demonstrates that most of these mutants retain the ability to assemble into U4/U6 and U4/U5/U6 snRNPs. Notably, although mutations at three positions in U6 that base-pair with U4 are lethal, mutations in the complementary residues in $\mathrm{U} 4$ are fully viable. Furthermore, compensatory mutations in $\mathrm{U} 4$ that restore base-pairing fail to suppress the phenotypes of the $\mathrm{U} 6$ mutations. This demonstrates a function for $\mathrm{U} 6$ independent of its role in base-pairing. Remarkably, two of the three essential regions in U6 identified genetically correspond to intron insertion points in two yeast species. A temperature-sensitive mutation at one of these sites is defective in the second step of splicing in vitro.

[Key Words: Saccharomyces cerevisiae; splicing; U6 snRNA; U4 snRNA]

Received September 25, 1990; revised version accepted October 23, 1990.

The removal of introns from mRNA precursors is an essential and often regulated step in the expression of eukaryotic genes. Splicing proceeds via a characteristic two-step transesterification reaction. In the first step, the 2 ' hydroxyl of an adenosine residue embedded in the intron attacks the phosphodiester bond that demarcates the $5^{\prime}$-splice site, releasing the $5^{\prime}$ exon and forming the so-called lariat intermediate. Attack of the phosphodiester bond that defines the 3'-splice site by the 3' hydroxyl of the $5^{\prime}$ exon results in the production of ligated exons and release of the intron as a lariat. Since this chemistry is apparently shared by group II introns, some of which are capable of autocatalytic self-splicing, it has been proposed that the enzymatic functions of the nuclear mRNA splicing machinery are also mediated by RNA (Sharp 1985; Cech 1986).

Indeed, five evolutionarily conserved small nuclear RNAs (U1, U2, U4, U5, U6 snRNAs) packaged in small nuclear ribonucleoprotein particles (snRNPs) are essential components of the eukaryotic splicing machinery (for review, see Sharp 1987; Maniatis and Reed 1987; Steitz et al. 1988). Comparisons between the yeast and metazoan spliceosomal RNAs have revealed unexpected variation in size and sequence (for review, see Guthrie and Patterson 1988). For instance, the yeast U1, U2, and U5 snRNAs are from two to six times larger than their mammalian homologs; interestingly, these differences in size can be accounted for by nonessential yeast-specific domains that separate regions of conservation (Igel

'These authors contributed equally to this work. and Ares 1988; Shuster and Guthrie 1988, 1990; Kretzner et al. 1990; D. Frank and C. Guthrie, unpubl.). In contrast, yeast U4 and U6 are conserved in size (Siliciano et al. 1987; Brow and Guthrie 1988), and, like their mammalian counterparts, are found base-paired to each other in a single snRNP (Bringmann et al. 1984; Hashimoto and Steitz 1984; Siliciano et al. 1987; Brow and Guthrie 1988).

Unlike U4, U6 is highly conserved at the primary sequence level, being $80 \%$ identical to metazoan U6 over half its length (Brow and Guthrie 1988). This extraordinary conservation argues for a key role for U6 in the splicing reaction. U6 is unusual in several other aspects: It lacks the 2,2,7-trimethylguanosine cap and binding site for the core $(\mathrm{Sm})$ proteins found in the other spliceosomal RNAs (for review, see Lührmann 1988), and it is transcribed by RNA polymerase III rather than RNA polymerase II (Kunkel et al. 1986; Krol et al. 1987; Reddy et al. 1987; Brow and Guthrie 1990|. On the basis of phylogenetic comparisons, it was proposed that the basepairing interaction between U4 and U6 snRNAs consists of two intermolecular helices termed stem I and stem II (see Fig. 1; Brow and Guthrie 1988). The stem I interaction was previously identified directly by psoralen crosslinking studies (Rinke et al. 1985). Recent data from mammalian in vitro assembly experiments, as well as studies in yeast, provide strong support for this model and indicate that both stems are required for the formation of the U4/U6 snRNP /Hamm and Mattaj 1989; Bindereif et al 1990; K. Shannon and C. Guthrie, in prep.l. 


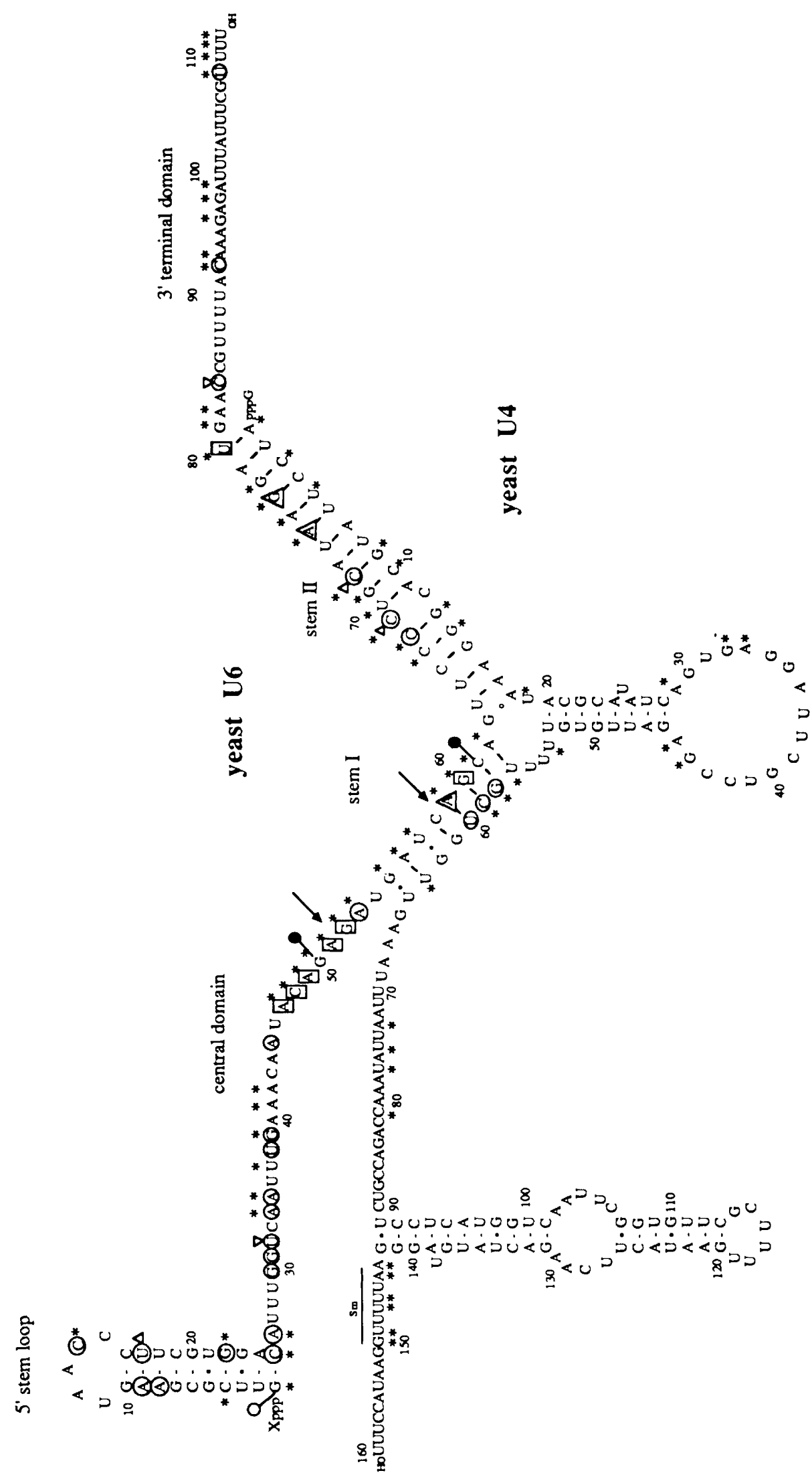

可施菏

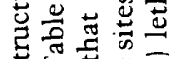

रिष्ठ

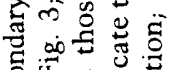

总出远竞

象

す

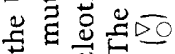

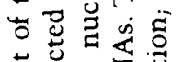

芯范范

d 0

需当り

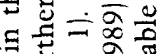

व

幽的苛可

है

क承茞

二

䓀品㤩

जิ

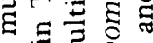

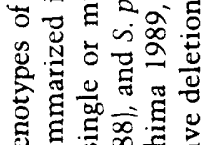

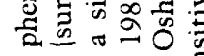

उत

ส

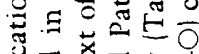

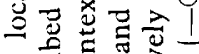

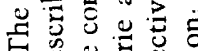

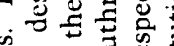

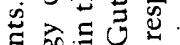

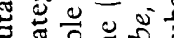

淢哥

范

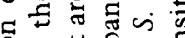

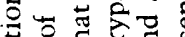

कु क

苛芯

है

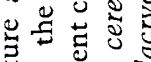

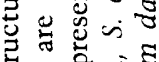

क 0 品

03 呵.

的空文

के

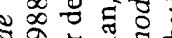

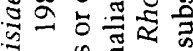

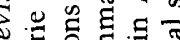

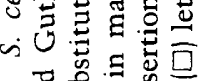

.

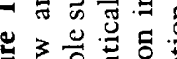

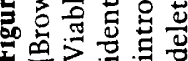


The assembly of the spliceosome is a highly ordered process that requires ATP hydrolysis. In both yeast and mammals, the U1 and U2 snRNPs are involved in substrate recognition by binding sequences located at the $5^{\prime}$ end and lariat branchpoint regions of the intron, respectively; these interactions are mediated in part by Watson-Crick base-pairing (Mount et al. 1983; Black et al 1985; Zhuang and Weiner 1986; 1989; Parker et al. 1987; Séraphin et al. 1988; Siliciano and Guthrie 1988; $\mathrm{Wu}$ and Manley 1989). Following binding of U1 and U2 snRNPs, the U5 and U4/U6 snRNPs assemble onto the pre-mRNA, possibly as a tripartite complex (Pikielny et al. 1986; Bindereif and Green 1987; Cheng and Abelson 1987; Konarska and Sharp 1987, 1988). Subsequently, U4 appears to be destabilized from the spliceosome or at least is subjected to a large conformational change; this event is accompanied by the appearance of splicing intermediates and products (Pikielny et al. 1986; Cheng and Abelson 1987; Lamond et al. 1988; Blencowe et al. 1989). Given that the native U4/U6 snRNP has a $T_{\mathrm{m}}$ of $53^{\circ} \mathrm{C}$ (Brow and Guthrie 1988), the destabilization of U4 is presumed to require an active process.

The temporal correlation between the apparent disruption of U4/U6 base-pairing and the nucleolytic steps of the splicing reaction has led to the hypothesis that the unwinding of the two RNAs allows U6 to be activated for participation in catalysis (Brow and Guthrie 1989). Such a model would also account for the observation that the sequence of U6 within the basepaired interaction domain shows higher conservation than the corresponding region of U4 (18 vs. 11 nucleotides, respectively) by proposing that the nucleotides in U6 are under dual functional constraints /Guthrie and Patterson 1988). According to this view, U4 might act primarily as a negative regulator, sequestering U6 in a catalytically inert conformation. A final motivation to the hypothesis was provided by the discovery of an mRNA-type intron in stem I of the Schizosaccharomyces pombe U6 gene (Tani and Oshima 1989): This intron may have arisen via an aberrant reverse splicing reaction, placing the region of intron insertion near potential catalytic residues (Brow and Guthrie 1989).

Here, we present the tirst detailed genetic analysis of the Saccharomyces cerevisiae U6 gene as a first step in testing the model that U6 plays a role in addition to base-pairing with $U 4$, conceivably in the chemical steps of splicing. Our strategy involved a combination of doped synthesis and site-directed mutagenesis to generate point mutations in U6; using a simple genetic screen, we then identified mutants with lethal or conditionally lethal phenotypes. Mutants of further interest are those that (1) produce stable U6 RNA, (2) assemble into U4/U6 and U4/U5/U6 snRNPs, and (3) ideally, enter the spliceosome and progress beyond the event of U4 destabilization. We report the identification of 12 positions at which single nucleotide substitutions or deletions result in lethal or temperature-sensitive phenotypes. The location, as well as the genetic and biochemical behavior of these mutants, suggests that highly conserved nucleotides within U6 are required for multiple steps in the splicing pathway; among these may be plausible candidates for residues that may be directly involved in the splicing reaction.

\section{Results}

\section{Mutant isolation}

We sought to identify point mutations in the yeast U6 snRNA that confer lethal and conditional lethal phenotypes. Toward this end, we synthesized the coding sequence of the S. cerevisiae U6 gene (SNR6) from degenerate oligonucleotides, as described in Figure 2A. A large library of mutant U6 genes was created by using this pool of mutagenized oligonucleotides to replace the wild-type U6 sequence present on a yeast-Escherichia coli shuttle vector (Fig. 2A; Materials and methods). To assess the content of the mutant library we have sequenced a limited number of randomly selected clones from the library; the frequency of single-nucleotide substitutions observed agrees with that expected from the initial level of oligonucleotide degeneracy (see Materials and methods).

SNR6 is a single-copy essential gene (Brow and Guthrie 1988). This allowed us to use a simple genetic screen based on the plasmid shuffle method (Boeke et al. $1987 /$ to identify lethal and conditional lethal mutants in the U6 snRNA (Fig. 2B). DNA prepared from the mutant library described above was introduced by transformation into the yeast strain YHMl, which contains a precise deletion of the yeast U6 gene (snr6::LEU2) complemented by a wild-type copy of U6 carried by a centromeric, URA3 plasmid. Approximately 5000 such yeast transformants, initially plated at $30^{\circ} \mathrm{C}$, were replica-plated to plates containing 5-fluoroorotic acid (FOA), which selects for cells that have lost the URA3marked plasmid. Cells that fail to grow on FOA therefore contain an SNR6 gene with a lethal mutation. Replica-plating onto FOA plates that are incubated at $18^{\circ} \mathrm{C}$ or $37^{\circ} \mathrm{C}$ allows the isolation of conditional mutants. To identify the mutation, DNA was isolated from the mutant strains and used to transform $E$. coli. The sequence of the U6-coding region was then determined for each mutant. In addition, we assessed the phenotype of the randomly selected mutants described above; all of these were viable.

In our genetic screen we expected to isolate a substantial fraction, but by no means all, of the possible lethal and conditional nucleotide substitutions in the yeast U6 snRNA; this expectation is borne out by the observation that mutants mapping to a conserved hexanucleotide comprise $4 / 12$ of the possible lethal point mutations in this region as determined by saturation site-directed mutagenesis (see below). Thus, because our screen is subsaturating (covering roughly one-third of possible point mutations), the absence of a particular mutant cannot be taken as evidence for its viability.

The yeast U6 snRNA can be described by five phylogenetically defined structural domains: the 5 ' stem-loop, a single-stranded central domain, stem I and stem II of 
A
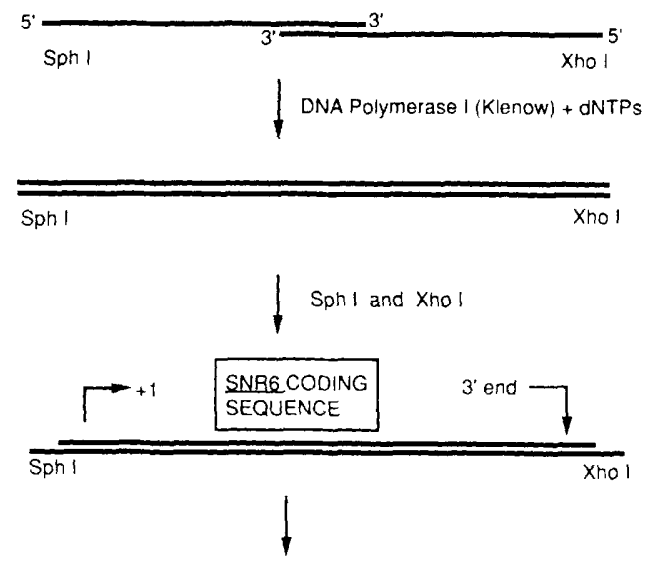

Ligate to pSX6 digested with Sph I and Xho I

\section{B}

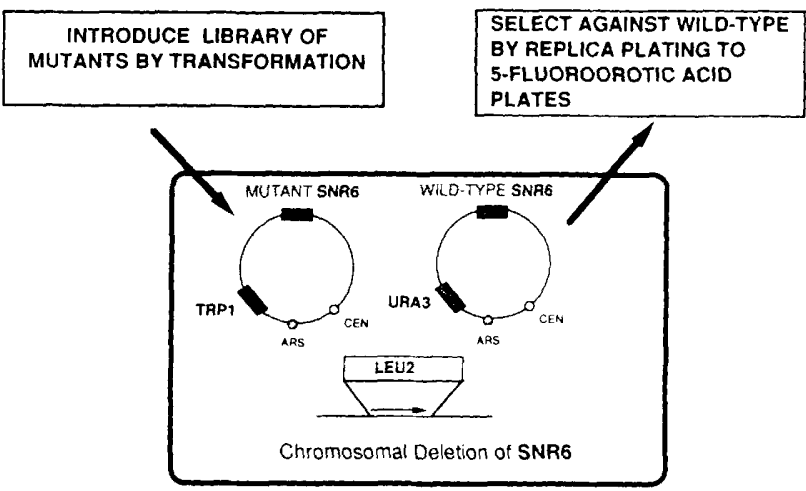

Figure 2. Scheme for isolation of U6 mutants. $|A|$ Synthesis of SNR6 from degenerate oligonucleotides. Black lines [top| represent two degenerate 82-nucleotide oligonucleotides synthesized as described in Materials and methods. The sense-strand oligonucleotide corresponds to nucleotides -13 to +69 in the numbering system of Brow and Guthrie (1988). The antisense strand oligonucleotide corresponds to nucleotides +130 to +49 $\left(5^{\prime}\right.$ to $\left.3^{\prime}\right)$. The oligonucleotides overlap by 21 nucleotides. In addition, each oligonucleotide contains mutations near their 5 ends that introduce restriction sites for SphI and XhoI, respectively. Identical sites were introduced into a genomic SNRG clone (producing pSX6). Following annealing and filling-in reactions, the double-stranded product was digested with SphI and $X$ hoI and ligated to pSX6 via the two restriction sites. Electroporation of $E$. coli resulted in the production of a library of $2 \times 10^{5}$ clones. (B) Genetic screen for SNR6 mutants based on the plasmid shuffle method (Boeke et al. 1987). DNA from the library described in $A$ was used to transform a strain harboring a deletion of the chromosomal SNR6-coding sequence, which is complemented by a URA3-marked plasmid containing a wildtype SNR6 gene. Cells that contain an introduced plasmid harboring a lethal mutation are identified by replica-plating of transformants onto plates containing FOA, which selects for loss of the URA3-marked plasmid. Inability to grow on FOA reflects a lethal mutation in the introduced copy of SNR6.

the U4/U6 interaction domain, and the $3^{\prime}$-terminal domain (Brow and Guthrie 1988; Guthrie and Patterson 1988; Fig. 1). The U6 mutants found using the mutagenesis strategy described above are shown in Table 1.
For lethal mutants, only single-nucleotide substitutions and deletions are listed, although we obtained a number of multiple mutants as well. In the case of the conditional mutants, three larger deletions are also shown, as these proved to be informative (see below). For viable mutants, both single- and multiple-nucleotide substitutions, as well as deletions and insertions, are listed, as these identify nucleotides that can be altered with no phenotypic consequences even in combination with other changes |although the possibility of intragenic suppression cannot be ruled out|. Of the 15 mutations identified as lethal or conditional lethal single-nucleotide substitutions or deletions (Table 1), all affect invariant residues 111 in total). Conversely, we obtained viable changes affecting a total of 21 nucleotides, 12 of which are invariant residues. The location and phenotypes of the point mutants listed in Table 1 are summarized in Figure 1 in the context of the structural model proposed by Brow and Guthrie (1988). Below, we describe these mutants in terms of this structure.

5' Stem-loop Most of the size variation observed in U6 snRNAs across evolution can be accounted for by differences in the 5' stem-loop /Guthrie and Patterson 1988; Roiha et al. 1989). As shown in Figure 1, few nucleotides in this domain are phylogenetically invariant: the $\mathrm{G}-\mathrm{C}$ pair at the base of the stem, a C-G pair within the stem, and the conserved $\mathrm{C}$ at position 14 in the loop. Our analysis indicates that changes in some of these conserved elements are viable (see Fig. 1). Deletion of the $\mathrm{G}$ at position 1 , however, results in a cold-sensitive phenotype, as do several other mutations containing changes at or near the transcription start site (Table 1 and data not shown). This phenotype may result from a transcriptional defect, consistent with the finding of Mattaj et al. (1988) that nucleotides around the start site of a Xenopus $\mathrm{U} 6$ gene are determinants of transcriptional efficiency. Interestingly, the mutation $\Delta U 3-G 7$ introduces a large disruption of the $5^{\prime}$ part of the stem-loop and results in cold sensitivity, whereas a mutation that deletes the $3^{\prime}$ half of the stem-loop, $\Delta U 21-C 25$, exhibits a more severe phenotype, growing very poorly and only at $30^{\circ} \mathrm{C}$ (Table 1). A potential explanation for this discrepancy is suggested by recent analysis of the promoter of the yeast $\mathrm{U} 6$ gene, which implicates an intragenic A block promoter element (spanning nucleotides 21-31) in the transcription of SNR6 by RNA polymerase III (Brow and Guthrie 1990). Thus, the phenotype of $\Delta U 21$ C25 may be due to a defect in transcription.

Central domain With the exception of mutations lying in the A block consensus sequence, we have not recovered mutations affecting $\mathrm{U} 6$ function in the $5^{\prime}$ threequarters of this region. In fact, numerous mutations that alter invariant nucleotides in this area have no phenotype (see Fig. 1). In contrast, a concentration of lethal and temperature-sensitive point mutations is found in the $3^{\prime}$ end of the central domain, in the sequence ACAGAGA positions $47-53$ ), which is invariant in all species examined (Guthrie and Patterson 1988). 
Table 1. U6 mutants

\begin{tabular}{|c|c|c|c|c|c|}
\hline & $\begin{array}{l}\text { 5' Stem-loop } \\
\text { |nucleotides } 1-25 \text { | }\end{array}$ & $\begin{array}{l}\text { Central domain } \\
\text { \{nucleotides } 26-53 \mid\end{array}$ & $\begin{array}{l}\text { Stem I } \\
\text { (nucleotides 54-62) }\end{array}$ & $\begin{array}{l}\text { Stem II } \\
\text { (nucleotides } 63-80 \text { ) }\end{array}$ & $\begin{array}{l}3^{\prime} \text {-Terminal domain } \\
\text { (nucleotides } 81-112 \text { ) }\end{array}$ \\
\hline Lethal & & $\begin{array}{l}\Delta \mathrm{C} 48 \\
\mathrm{C} 48 \mathrm{~A}(2) \\
\mathrm{C} 48 \mathrm{U}(3) \\
\Delta \mathrm{A} 49 \\
\mathrm{~A} 49 \mathrm{G}(1) \\
\mathrm{G} 52 \mathrm{~A}(1)\end{array}$ & $\begin{array}{l}د \mathrm{~A} 59 \\
\Delta \mathrm{G} 60 \\
\text { G60U (2) }\end{array}$ & $\begin{array}{l}\Delta A 75 \\
\Delta G 77 \\
\text { U80G }(2)\end{array}$ & \\
\hline $\begin{array}{l}\text { Temperature } \\
\text { sensitive }\end{array}$ & $\Delta \mathrm{U} 21-\mathrm{C} 25$ & $\Delta \mathrm{A} 47$ & $\mathrm{C} 61 \mathrm{G}|3|$ & & \\
\hline $\begin{array}{l}\text { Cold } \\
\text { sensitive }\end{array}$ & $\begin{array}{l}\Delta \mathrm{G} 1 \\
\Delta \mathrm{U} 3-\mathrm{G} 7 \\
\Delta \mathrm{U} 21-\mathrm{C} 25\end{array}$ & & & & $\Delta U 90-G 98$ \\
\hline Viable & $\begin{array}{l}\text { A8U } \\
\text { A9C** } \\
\text { G1Ai } \\
\text { C14A } \\
\Delta U 17 \\
\text { G22U } \\
\text { C25U* }\end{array}$ & $\begin{array}{l}\text { A26U* } \\
\text { G30A } \\
\text { G31A** } \\
\Delta U 32 \\
\text { A34U G39A } د C 72 \\
\text { A34C C68G C92U } \\
\text { A35U } \\
\text { A35U U109C } \\
\text { U38A } \\
\text { A45C* } \\
\text { A45U* }\end{array}$ & & $\begin{array}{l}\Delta \mathrm{C} 69 \\
\text { A34U G39A } \triangle \mathrm{C} 72 \\
\text { A34C C68G C92U }\end{array}$ & $\begin{array}{l}\Delta \mathrm{C} 84 \\
\Delta \mathrm{U} 88-\mathrm{U} 90 \\
\text { A34C C68G C92U } \\
\text { A35U U109C }\end{array}$ \\
\hline
\end{tabular}

The phenotype and location of mutants isolated in the screen described in Fig. 2 are summarized. Nomenclature is as follows: For a point substitution, the wild-type nucleotide and its position are followed by the mutant nucleotide; nucleotide deletions are designated by a $\Delta$ preceding the wild-type nucleotide and position; insertion of a nucleotide is indicated by an " $\mathrm{i}$ " following the mutant nucleotide. Only single nucleotide substitutions and deletions are listed for lethal and conditional lethal mutants, with the exception of three conditional deletion mutants involving more than one nucleotide (see text). For viable mutants, both single and multiple mutants are shown. The multiple mutants are duplicated, appearing in all columns corresponding to the region of each change (boldface type) found in that mutant. Randomly selected clones from the mutant library, previously constructed site-directed mutants $\left({ }^{*}\right)$, and mutants that initially screened as lethal but were found to be viable upon retesting $\left.\left.\right|^{*}\right)$ account for those mutants listed under viable. The number in parenthesis indicates the number of independent isolates obtained for a particular mutation.

Stem I We also recovered several lethal and temperature-sensitive nucleotide substitutions and deletions in the conserved stem I region (Fig. 1; Table 1), in the trinucleotide AGC (positions 59-61). Interestingly, this cluster of lethal mutations is in a region that base-pairs with U4 snRNA.

Stem II This helix, like stem I, is highly conserved in primary sequence (11 invariant residues out of 17). In contrast to the central domain and stem I, we recovered only one lethal single-nucleotide substitution in this domain, U80G (recovered twice). However, given the subsaturating extent of our mutagenesis, there may well be other lethal single-nucleotide substitutions in this domain. Two other single-nucleotide deletions in this region are lethal $(\Delta A 75$ and $\Delta G 77)$. Notably, deletions in stem II per se do not always result in lethality: Deletion of positions 69 or 72 (in A34U G39A $\triangle \mathrm{C} 72$ ) and substitution of position 68 (A34C C68G C92U) are viable.

$3^{\prime}$-Terminal domain This region is poorly conserved in sequence but is between 29 and 32 nucleotides in all species. This strict size conservation may reflect structural constraints. Consistent with this notion, we recovered no lethal point mutations in this domain. However, alterations in the length of the $3^{\prime}$-terminal domain, such as deletion of nucleotides 90-98 (Table 1) and insertion of 4 nucleotides after position 86 in a complex mutant (data not shown), each result in a leaky cold-sensitive phenotype.

In summary, our genetic screen allowed us to recover 15 point mutations (single-nucleotide substitutions or deletions) identifying 11 positions of the U6 snRNA that confer lethal or conditional phenotypes. These nucleotides map to five regions of the molecule: position 1, the ACAGAGA box in the central domain, the trinucleotide AGC in stem I of the U4/U6 interaction domain, and the 3 '-terminal nucleotide of stem II. Our interest in the ACAGAGA and AGC motifs was spurred further by the finding that they are interrupted by unusual mRNA-type introns in the yeast species Rhodosporidium dacryoidum (ACAGA/G; " " indicates intron position) and S. pombe (/AGC) (Tani and Oshima 1989, and pers. comm.). These observations led us to investigate these two regions in more detail.

\section{Saturation mutagenesis of the ACAGAGA box}

We constructed all possible single-nucleotide substitutions in the ACAGAGA box (positions 47-53 in Fig. 1) 


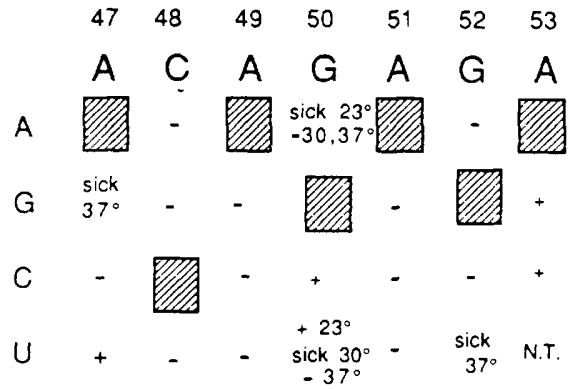

Figure 3. Phenotypes of mutations in the invariant ACAGAGA motif. The phenotypes of the U6 mutant were determined using the plasmid shuffle method as described in Fig. $2(B) .|-|$ Lethal at all temperatures; $|+|$ viable at all temperatures; (N.T.) not tested.

by oligonucleotide-directed mutagenesis. The U6 point mutants were subcloned into the vector pSE358 [CEN, TRP1) and transformed into YHM1, and their phenotypes were assessed by the plasmid shuffle method. The results are summarized in Figure 3. Notably, despite the small size ( 7 nucleotides) of the mutagenized region, we obtained a complex array of mutant phenotypes. Any change in positions 48,49 , and 51 results in lethality. Substitution of G52 by an A or a C is also lethal; a U, however, results in leaky temperature sensitivity. The phenotype of mutants at position 47 also depends on the nucleotide substitution: $\mathrm{a} C$ is lethal, a $\mathrm{U}$ is viable, and a $\mathrm{G}$ results in a leaky temperature-sensitive phenotype. Curiously, a deletion of nucleotide 47 , which brings the nucleotide at position 46, a $\mathrm{U}$, into position 47 (creating the sequence UCAGAGA), is not fully viable but exhibits leaky temperature-sensitive growth (Table 1 ). This may reflect spacing constraints in this region. A spectrum of phenotypes is also seen at position 50: Substitution of this $\mathrm{G}$ with a $\mathrm{C}$ is viable at all temperatures, a $U$ is temperature-sensitive, and an A allows the cells to grow very poorly at $18^{\circ} \mathrm{C}$ or $23^{\circ} \mathrm{C}$ and not at all at higher temperatures. Changing the nucleotide $\mathrm{A} 53$ to a $\mathrm{G}$ or a $\mathrm{C}$ has no effect on growth.

\section{Asymmetric phenotypes in the U4/U6 interaction domain}

Since the invariant nucleotides AGC in stem I are part of a phylogenetically conserved intermolecular helix (Fig. 1), a straightforward explanation for the lethal phenotypes of stem I mutants is that they are defective in base-pairing with U4 snRNA. This hypothesis makes two predictions: (1) Analogous mutations in $U 4$ that disrupt stem I should have a deleterious phenotype; and (2) compensatory mutations in U4 that restore basepairing in stem I should suppress the lethal or temperature-sensitive phenotype of the U6 stem I mutants, as has been shown for mutants in stem II (K. Shannon and C. Guthrie, unpubl.).

To test this hypothesis, we constructed eight mutations in the yeast U4 gene (which is encoded by the SNR14 gene; Siliciano et al. 1987) in stem I at positions that base-pair with the conserved AGC trinucleotide in U6 described above (positions 58, 59, and 60 in SNR14). The U4 mutant genes were subcloned into the pSE362 vector (CEN, HIS3) and transformed into a strain containing a disruption of the chromosomal U4 gene (snr14 :: TRP1). Their phenotypes were tested using the plasmid shuffle method and are shown in Table 2. Surprisingly, all U4 mutant strains were viable at every temperature tested and exhibited no detectable growth defects (Table 2, column 1). To test whether or not compensatory mutations in $\mathrm{U} 4$ could suppress the phenotype of U6 mutants in stem I, U4 mutants at position 59, which base-pairs with position 60 in U6, were introduced in strains containing a deletion of the chromosomal U6 gene and either of the two lethal U6 mutant RNAs at position 60 (G60U or G60C; G60C was constructed by site-directed mutagenesis). In addition, they also contained a rescuing U6 wild-type gene on a URA3marked plasmid. The resultant strains failed to grow on FOA, indicating an inability to lose the wild-type U6 URA3-marked plasmid, regardless of the $\mathrm{U} 4$ mutant introduced (Table 2). Moreover, transformation of a strain harboring the temperature-sensitive mutation C61G with the $\mathrm{U} 4$ genes mutated at position 58 , results in no suppression: Such strains are viable at $18-34^{\circ} \mathrm{C}$ but fail to grow at $37^{\circ} \mathrm{C}$, regardless of the $\mathrm{U} 4$ allele present (Table 2). We cannot rule out the possibility that the U4 compensatory mutants exhibit a recessive defect that prevent them from competing with the wild-type U4 for association with U6. This seems unlikely, however, since strains harboring only the mutant $\mathrm{U} 4$ genes have no obvious growth defects. Taken together, these results indicate that the lethality of the U6 stem I mutations cannot be attributed (solely) to defects in base-pairing with the U4 snRNA.

\section{RNA accumulation of lethal U6 mutants}

It is important to determine whether the phenotype of lethal U6 mutants might be due to defects in their ex-

Table 2. Phenotypes of mutations in stem I of U4 and U6

\begin{tabular}{lcccc}
\hline & \multicolumn{5}{c}{ U6 } \\
\cline { 2 - 5 } U4 & Wild type & G60U & G60C & C61G \\
\hline WT & + & - & - & ts \\
G58A & + & & & ts \\
G58C & + & & & ts \\
G58U & + & - & - & ts \\
C59A & + & - & - & \\
C59G & + & - & - & \\
C59U & + & & & \\
U60A & + & & & \\
U60C & + & & &
\end{tabular}

Columns represent SNR6 alleles; rows correspond to SNR14 alleles. The intersection of the two describes the phenotype of that combination of alleles: $|+|$ Fully viable; $|-|$ lethal; ts, temperature-sensitive. Blank boxes represent combinations not tested. Note that strains containing both mutant SNR6 and SNR14 alleles also contain the chromosomal wild-type copy of SNR14. 
pression and/or stability, as opposed to functional defects per se. We thus assessed RNA levels in vivo by Northern hybridization. Since these mutants are inviable in the absence of a wild-type U6 gene, this analysis had to be performed on heterozygous strains containing both mutant and wild-type U6 RNAs. Due to similarities in sizes, however, these two RNAs could not be resolved by gel electrophoresis. To circumvent this problem, we constructed a "pseudo-wild-type" U6 gene (U6-5'Sp) in which the 25-nucleotide $S$. cerevisiae 5' stem-loop is replaced by the 12-nucleotide $5^{\prime}$ stemloop of S. pombe (nucleotides 1-12; Tani and Oshima 1989|; the remainder of this hybrid encodes wild-type $S$. cerevisiae U6 sequences. The U6-5'Sp chimeric RNA was cloned into the vector pSE360 (CEN, URA3), and a strain derived from YHMl was constructed in which this gene was the sole copy of U6. The growth rate of this strain is identical to the wild-type parent (data not shown). Various U6 mutants cloned into pSE358 (CEN, TRP1) were transformed into this strain to generate heterozygotes, as diagramed in Figure 4A. Since the chimeric RNA is only 99 nucleotides in length, compared to 112 nucleotides in the case of point substitutions, the two U6 species can be separated easily by electrophoresis through denaturing polyacrylamide gels.

Northern analyses were performed as described in Materials and methods. The results are shown in Figure 4B. In a control heterozygous strain containing a copy of both the pseudo-wild-type (U6-5'Sp) and wild-type U6 genes, the pseudo-wild-type RNA is found at approximately threefold lower steady-state levels las determined by densitometric scanning/ compared to the wildtype U6 snRNA (Fig. 4B, lane 23). This is likely to be due to differences in transcriptional efficiency since the re- placement of the S. cerevisiae $5^{\prime}$ stem-loop with that of $S$. pombe alters the A block consensus sequence found at positions 21-31 (Brow and Guthrie 1990). As expected, a deletion in the A block in the mutant $\Delta \mathrm{U} 21$ C25 results in barely detectable amounts of RNA compared to the pseudo-wild-type internal control (Fig. 4B, lane 241. Interestingly, this deletion mutant actually grows at $30^{\circ} \mathrm{C}$, albeit slowly, demonstrating that a drastic reduction in U6 RNA levels can be tolerated without preventing growth. This is consistent with the fact that $\mathrm{U} 6$ is present in yeast in 5- to 10 -fold excess over U4 (Siliciano et al. 1987; D. Brow and C. Guthrie, unpubl...

As shown in Figure 4B, point mutations in the ACAGAGA box at positions 47 (lanes $3-5$ ) and 52 (lanes $18-20 \mid$, as well as substitutions at position 50 (lanes $12-14$, result in RNA levels comparable to the pseudowild-type RNA. Similarly, Northern analysis of the six lethal mutants in stem I and stem II of the interaction domain demonstrates that they are stable in heterozygous strains (Fig. 4B, lanes 25-30). In contrast, mutants at positions 48 and 49 (lanes 6-11) and, to a lesser extent, position 51 (lanes 15-17) contain three- to fivefold less steady-state levels of RNA. This is unlikely to be due to a transcriptional defect since genes with multiple changes in the ACAGAGA box are transcribed as well as the wild-type gene (data not shown) in an in vitro yeast transcription system (Brow and Guthrie 1990).

The decreased steady-state levels of mutants at positions 48-51 may be a consequence of defects in snRNP formation and/or stability. In this regard, it is interesting to note that the amount of the U6-5'Sp RNA in all the heterozygous strains carrying a mutant U6 gene is threefold higher than in a heterozygous strain carrying the

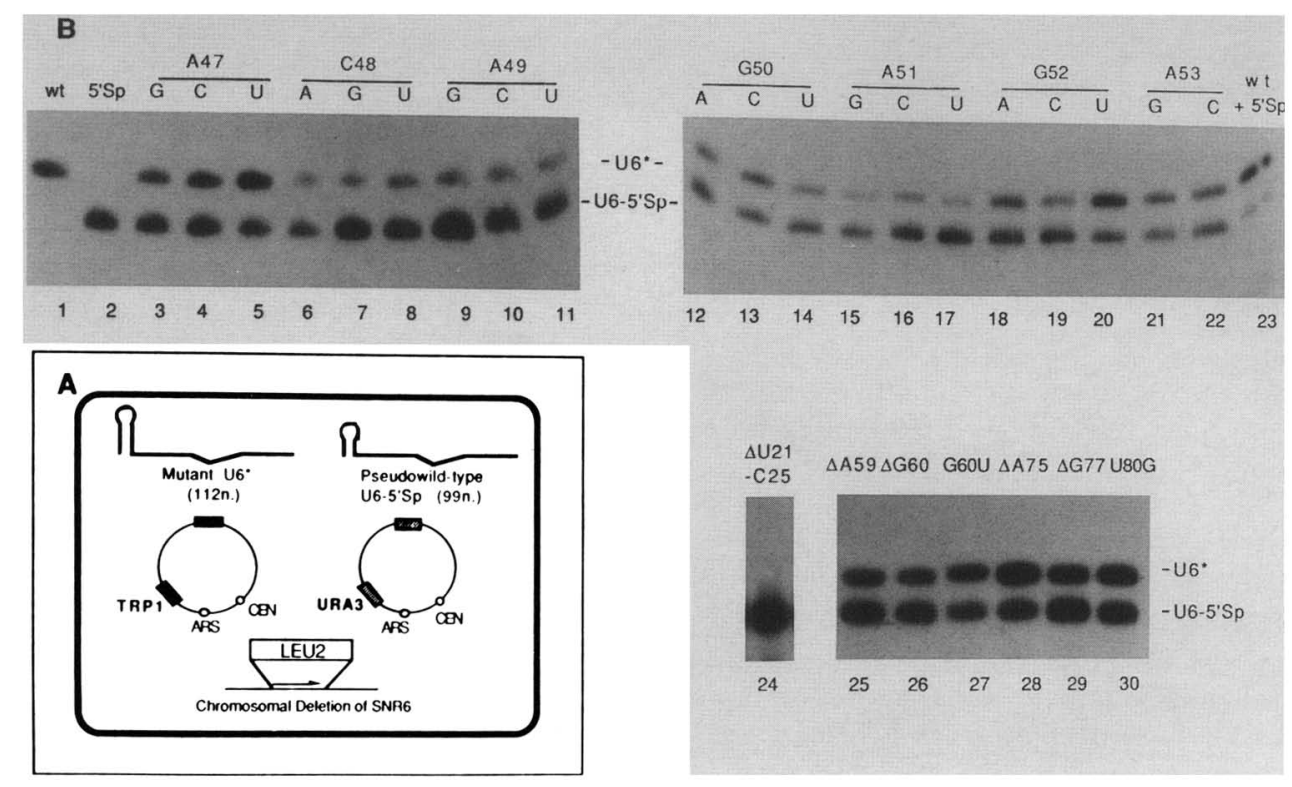

Figure 4. Northern analysis of U6 mutants. $(A)$ Schematic representation of the heterozygous strains carrying both the pseudo-wildtype U6-5'Sp chimera and various U6 mutants $\left(U 6^{*}\right) .(B)$ Northern blot of total RNA prepared from heterozygous strains. The probe is complementary to nucleotides $92-112$ of yeast U6. Lanes $w t, 5^{\prime} \mathrm{Sp}$, and $w t+5^{\prime} \mathrm{Sp}$ correspond to strains carrying only the wild-type U6 gene, the U6-5'Sp gene, and both wild-type and U6-5'Sp U6 genes, respectively. Mutants are listed above each lane. 
wild-type U6 gene (Fig. 4, cf. all lanes with lane 23). One possible explanation for this is that the mutant RNAs compete less well than the wild-type U6 snRNA for factors involved in snRNP formation and/or stability. However, the same effect is observed in heterozygous strains carrying fully viable alleles (e.g., A47U and mutations at position 53). This and the observation that large reductions in the steady-state level of U6 can be tolerated (see above) indicate that the lethality of mutants in the ACAGAG hexanucleotide cannot be explained solely by defects in snRNP formation and/or stability, although it may contribute to the phenotype.

\section{Assembly of U6 mutant RNAs into U4/U6 and U4/U5/U6 snRNPS}

Another potential explanation for the phenotype of lethal U6 mutants is defective snRNP-snRNP interactions. To test this possibility we took advantage of our previous demonstration that the three particles containing U6 (U6, U4/U6, and U4/U5/U6 snRNPs) can be separated by velocity sedimentation on glycerol gradients (Bordonné et al. 1990). Extracts prepared from heterozygous strains used in the Northern hybridization experiments were fractionated on $10-30 \%$ glycerol gradients, and the RNA was analyzed by Northern hybridization probing simultaneously for $\mathrm{U} 4, \mathrm{U} 5$, and $\mathrm{U} 6$ snRNAs.

The results are shown in Figure $5(A-E)$. The control extract was made from a strain containing both wildtype U6 and chimeric U6- $5^{\prime}$ Sp genes. As can be seen in Figure 5A, three different particles are resolved: free U6 snRNP (fractions 17-21), U4/U6 snRNP (fractions 13-15), and U4/U5/U6 snRNP (fractions 1-5). Most U6 is found as free snRNP or in the U4/U5/U6 snRNP. Curiously, despite the fact that the U6-5'Sp RNA is found at levels threefold lower than the wild-type U6 RNA in fractions 17-21 containing free U6 snRNP, it is present in equimolar amounts in fractions containing the U4/U5/U6 snRNP (fractions $1-5$ ); the reason for this is unknown.

As expected from the Northern analysis, the ratios of mutant to pseudo-wild-type RNA in the free U6 snRNP fractions of the gradients of lethal U6 mutants (Fig. $5 \mathrm{~B}-\mathrm{E}$ ) are consistent with a range of defects in stable snRNP formation, with C48G (Fig. 5B) exhibiting the greatest difference and U80G (Fig. 5E) being expressed as well as the pseudo-wild-type. Despite these differences, one can assess the ability of a given mutant to form multi-snRNP complexes on a "per molecule" basis by comparing the ratio of mutant to pseudo-wild-type RNA in fractions containing free U6, U4/U6, and U4/U5/U6 snRNPs.

The extreme instability of the C48G mutant (Fig. 4B, lane 7) makes the interpretation of the gradient analysis of this mutant difficult. An overexposure of the autoradiogram is shown in Figure 5B. Some mutant RNA can be observed in the U4/U6 and U4/U5/U6 snRNP-containing fractions; however, the ratio of mutant to pseudo-wild-type RNA is lower than that found in the free U6 snRNP-containing fractions /cf. lanes 1-5 with 17-21), suggesting some defect in snRNP-snRNP interaction(s) in this mutant. An identical pattern was observed for another relatively unstable mutant A49G (data not shown).

Another mutant in the ACAGAG region, A51C (Fig. $5 \mathrm{Cl}$, appears to retain the ability to interact with $\mathrm{U} 4$ and U5 (witness the ratio of mutant to pseudo-wild-type RNA in fractions 1-3,9-13, and 15-19), as does the stem I mutant G60U (Fig. 5D). Analysis of the G50A and G52A mutants, as well as the stem I mutants $\Delta \mathrm{A} 59$ and G60C, indicate that these mutants are similarly assembled into U4/U6 and U4/U5/U6 particles/data not shown). In contrast, the lethal mutant in the terminal base pair of stem II (U80G), which is expressed as well as the pseudo-wild-type internal control, exhibits a severe defect in snRNP-snRNP interaction. This mutant barely forms appreciable amounts of U4/U6 or U4/U5/ U6 snRNPs in heterozygous extracts (Fig. 5E; cf. ratios of U6 RNA found in fractions $1-5$ and $17-21$ ).

In summary, these results indicate that most mutants in the ACAGAGA motif and the stem I region still retain the ability to form U4/U6 and U4/U5/U6 snRNPs despite varying degrees of stable RNA accumulation; thus, they may be defective in steps downstream of the formation of the U4/U5/U6 snRNP. It is therefore of interest to determine whether these mutant snRNPs are assembled into the spliceosome. Unfortunately, we have been unable to assess this parameter because of the difficulty in isolating sufficient quantitites of yeast splicing complexes to quantitatively analyze mutant and wildtype RNA composition by Northern hybridization.

\section{The efficiency of the second step of the splicing reaction is decreased in the G50A mutant}

To assess the defective function of U6 snRNAs harboring temperature-sensitive mutations, we have examined their activities in vitro. Splicing was examined in extracts prepared from strains carrying one of three temperature-sensitive alleles, G50A, G50U, or G52U, as their sole copy of U6. Particularly interesting was the mutant G50A, which shows a severe growth defect, even at permissive temperature (Fig. 3). Incubation of radioactive actin mRNA precursor in a splicing extract prepared from this strain results in successful completion of the first step of splicing, but a drastic decrease in the efficiency of the second step of the reaction $13^{\prime}$-splice site cleavage and exon ligation) both at $15^{\circ} \mathrm{C}$ (cf. the ratio of lariat to lariat intermediate in Fig. 6A, B, lanes 3 ) and at $23^{\circ} \mathrm{C}$ (Fig. 6A, lane 6). In contrast, the efficiency of splicing in an extract prepared from G50U and G52U strains (Fig. 6A, lanes 4, 5, 7, and 8; Fig. 6B, lane 5) is comparable to that found for a wild-type extract (Fig. 6A, lane 1; Fig. 6B, lane 21. This correlates with the superior growth phenotypes of G50U and G52U compared with the G50A mutant. Identical results were obtained with an independent G50A extract (Fig. 6B, lane 4), indicating that the decrease in the efficiency of the second step of splicing is not due to variation in extract preparation. 


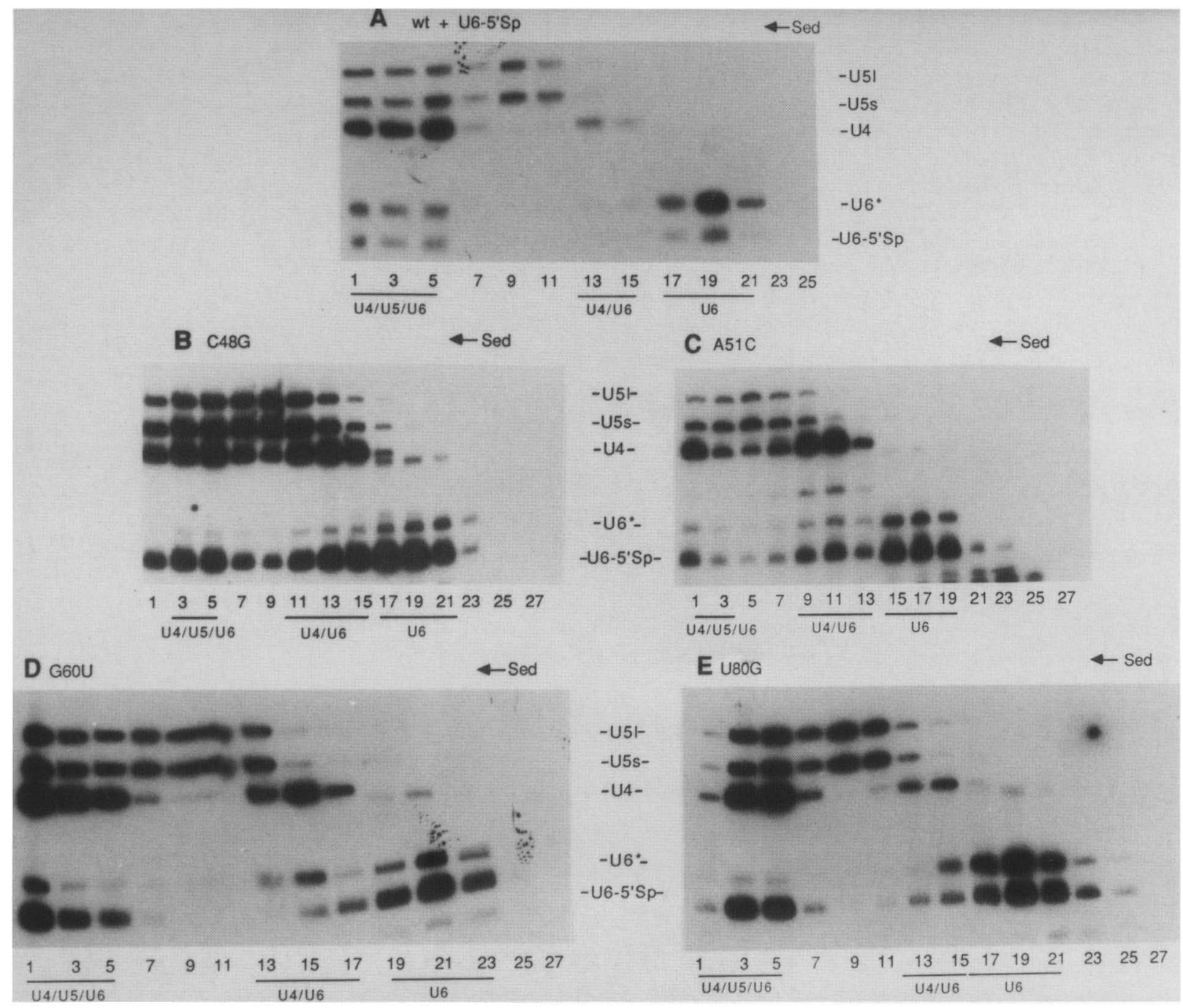

Figure 5. Velocity sedimentation analysis of U6 mutants. Splicing extracts were prepared from heterozygous strains carrying both the pseudo-wild-type U6-5'Sp chimera and either a wild-type U6 gene $(A)$ or the indicated mutant $(B-E)$. The extracts were fractionated on $10-30 \%$ glycerol gradients, without prior incubation with ATP and in the absence of precursor mRNA as described previously (Bordonné et al. 1990). RNA present in odd-numbered fractions was analyzed by Northern hybridization using probes complementary to yeast U4, U5, and U6 snRNAs. The RNA species, the positions of U6, U4/U6, and U4/U5/U6 snRNPs, as well as the direction of sedimentation, are indicated.

The defect of the G50A extract can be complemented with a U6-containing, snRNP-enriched fraction (fraction I; Cheng and Abelson 1986) from a wild-type extract (Fig. 6A, lane 9). The slight decrease in the amount of lariat intermediate observed in the G50A extract compared to wild type (Fig. 6A, cf. lanes 3 and 6 with lane 1) is also ameliorated by the addition of fraction I (lane 9), suggesting that the G50A mutant may have a small effect on the first step in addition to its substantial defect in the second step of the splicing reaction.

\section{Discussion}

Mutagenesis identifies 12 critical residues in U6 snRNA

Of the five RNAs required for the splicing of mRNA precursors (U1, U2, U4, U5, and U6 snRNAs), only two have been assigned specific functions: In both yeast and mammals, the U1 and U2 snRNAs interact with the intron substrate, in part by Watson-Crick base-pairing (see introductory section for references). In contrast, little is known regarding the roles of the U4, U5, and U6 spliceosomal RNAs. Of the three, U6 is by far the most conserved in size and sequence, implying strong functional constraints; it is therefore a particularly attractive target for genetic studies. Previous functional analysis of yeast spliceosomal RNAs by site-directed mutagenesis revealed a surprising tolerance to point mutations, even when phylogenetically invariant nucleotides were altered. Examples include the dispensability of the conserved loop IV sequence of U2 [Shuster and Guthrie $1990)$, the flexibility of the highly conserved $\mathrm{A}\left(\mathrm{U}_{3-6}\right) \mathrm{G}$ Sm-binding site in U5 snRNA (Jones and Guthrie 1990), 


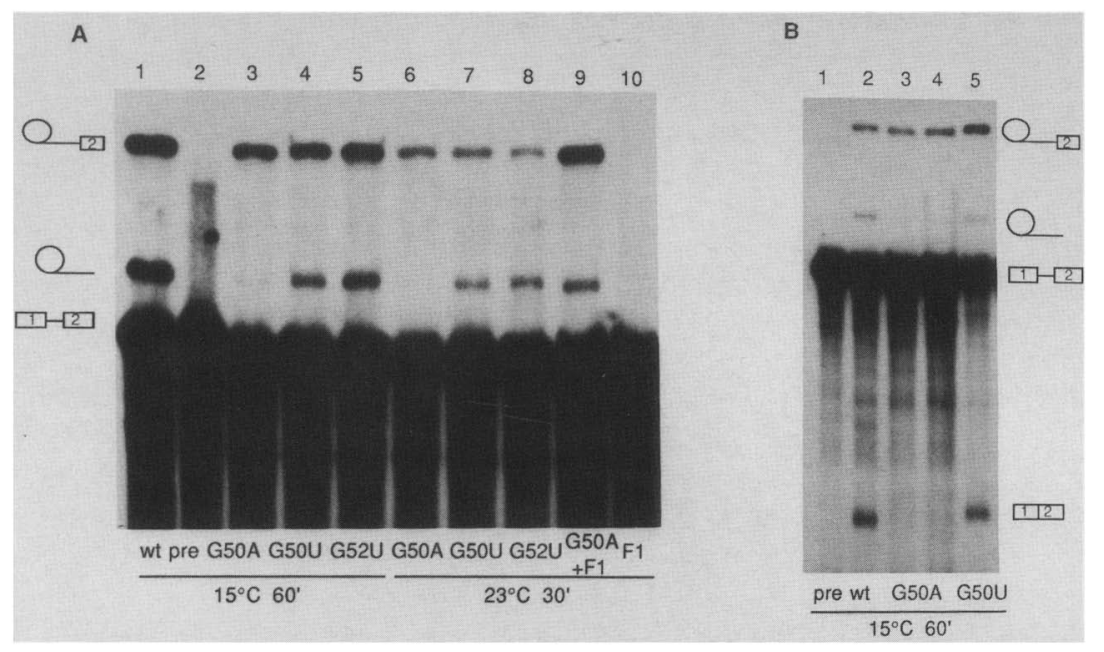

Figure 6. Splicing activity of mutant U6 extracts. Extracts prepared from wild-type, G50A, G50U, and G52U strains were assayed for splicing at $15^{\circ} \mathrm{C}$ for $60 \mathrm{~min}$ or at $23^{\circ} \mathrm{C}$ for $30 \mathrm{~min}$ under standard splicing conditions (Lin et al. 1985), using a ${ }^{32} \mathrm{P}-\mathrm{la}$ beled in vitro-transcribed yeast actin premRNA. Reaction products were separated on $6 \%$ denaturing polyacrylamide gels. The identity of the reaction products is shown. (pre) Precursor RNA incubated without splicing extract. $|A|$ The autoradiogram is an overexposure to observe the lack of intron lariat in lanes 3 and 6 . The complementation experiment (lane 9) was performed by mixing $4 \mu \mathrm{l}$ of G50A extract with $1 \mu \mathrm{l}$ of fraction 1 from a wild-type extract. The reaction was initiated by the addition of the other components of the splicing reaction. (Lane 10) Splicing reaction performed with $2 \mu \mathrm{l}$ of fraction I only. The lack of mature mRNA in G50A extracts is shown in $B$. Lanes 3 and 4 in $B$ represent two independent G50A splicing extract preparations.

and the viability of most point mutations in the invariant loop of U5 snRNA (B. Patterson, D. Frank, and C. Guthrie, unpubl.). Finally, even several mutants in the invariant $5^{\prime}$ end of $U 1$ snRNA, which interacts directly with the intron by base-pairing, are viable (Séraphin et al. 1988; Siliciano and Guthrie 1988). This apparent tolerance may reflect subtle contributions of particular invariant residues, or redundant interactions. Conversely, the clusters of lethal point mutations identified at the $5^{\prime}$ end of Ul snRNA or in the branchpoint recognition domain of U2 snRNA reflect critical and highly constrained interactions between these snRNAs and the intron (Parker et al. 1987; Séraphin et al. 1988; Siliciano and Guthrie 1988; T. Simmons, J. Milligan, and C. Guthrie, unpubl.).

Because of the difficulty in identifying critical nucleotides in spliceosomal RNAs by site-directed mutagenesis, we have first employed a genetic screen to identify lethal point mutations in the yeast U6 snRNA. By coupling a generally applicable strategy for uniformly mutagenizing the U6 gene with such a screen and then performing further site-directed mutagenesis, we have succeeded in identifying 12 positions in the U6 snRNA at which substitution or deletion of a single nucleotide is a lethal or temperature-sensitive event. Six of these positions lie in the U4/U6 interaction domain, whereas the other six cluster in an invariant hexanucleotide upstream of the interaction domain. Further genetic and biochemical analyses of these mutant RNAs suggest that the sensitivity of these particular conserved residues to mutation reflects important roles for $\mathrm{U} 6$ at multiple points in the splicing pathway.

\section{A point mutation in stem II blocks formation of the U4/U6 SnRNP}

We have shown by Northern analysis and velocity sedimentation experiments that most mutants in the conserved hexanucleotide and in stem I of U6 are stable and retain the ability to assemble into U4/U6 and U4/U5/U6
snRNPs. In contrast, a point mutation in the terminal base pair of stem II of the U4/U6 interaction domain (U80G), while producing stable U6 RNA, almost completely abolishes formation of U4/U6 and U4/U5/U6 snRNPs, implicating this conserved residue in the association of U4 and U6 snRNAs during the splicing cycle. The defect in U80G seems unlikely to be due merely to disruption of the U4/U6 base-pairing interaction, however, since three mutants that are predicted to reduce base-pairing in stem II to an equal or greater degree are fully viable (Table 1). Further genetic analysis, including the testing of the effect of a compensatory mutation in U4 that restores base-pairing with this mutant, is needed to resolve this issue.

\section{Asymmetric roles for U4 and U6 in stem I}

We have found that stem I of the U4/U6 interaction domain harbors crucial residues on the U6 side of the helix in the conserved trinucleotide AGC (positions 59-61). Strikingly, the presumptively base-paired residues in U4 are not required for function in vivo despite the fact that two of these are phylogenetically invariant. Furthermore, compensatory mutations in U4 that restore basepairing with lethal or conditional lethal U6 mutants fail to suppress the biological phenotypes. We conclude that those residues in U6 play a role in splicing independent of base-pairing with U4. Since lethal mutants in this region produce stable U6 RNA and the mutant U6 snRNPs associate with U4 and U5 snRNPs, we propose that the invariant AGC trinucleotide functions in critical interactions downstream of the formation of the U4/U5/U6 snRNP (see below).

The observation that all eight mutations at positions 58-60 in stem I of U4 are tolerated, together with the finding that three point substitutions in stem II in U6 are viable, suggests that the precise structural character of the U4/U6 base-pairing interaction may be relatively flexible. Indeed, inspection of the structure of the U4/U6 helices from various species reveals some variation in 
helix lengths and placement of bulges; however, the overall extent of base-pairing remains relatively constant, suggesting that it is the main functional parameter (Guthrie and Patterson 1988). Given the asymmetry between $\mathrm{U} 4$ and $\mathrm{U} 6$ described above, one role for the base-pairing interaction may be to attach U6 to U4 for delivery to the spliceosome via interactions between $U 4$ and other factors. This is consistent with the observation that the 5' stem-loop of U4, which is required for the binding of the PRP4 protein (Xu et al. 1990), is also required for the association of the U4/U6 snRNP with the U5 snRNP (Bordonné et al. 1990).

\section{A mutation in the ACAGAG hexanucleotide is defective in a late step of splicing}

Construction of all possible nucleotide substitutions in the ACAGAG hexanucleotide revealed that all positions are required for U6 function; interestingly, in several cases, different changes at a single nucleotide gave rise to different biological phenotypes. For instance, changing A47 to a $\mathrm{C}$ is lethal, a $\mathrm{G}$ is temperature-sensitive, and a $U$ is viable (Fig. 3). Notably, this pattern of phenotypes does not correlate with the ability of A47 to engage in Watson-Crick base-pairing; in that case, both $\mathrm{C}$ and $\mathrm{U}$ changes would be equally deleterious. In this regard, it is useful to consider our data in terms of a model proposed by McPheeters et al. (1989), which proposes base-pairing between a conserved region of $\mathrm{U} 2$ snRNA just downstream of the branchpoint interaction domain and the ACAGAG region in U6. The appeal of this hypothesis is that it would juxtapose highly conserved regions of U6 with the intron branchpoint. However, as the pattern of mutant phenotypes in the ACAGAG hexanucleotide (at positions 47, 50, and 52) does not correlate with the expected disruption in basepairing, our data do not lend immediate support to this model.

Although mutants at positions 48 and 49 accumulate very low levels of U6 RNA, perhaps reflecting disruption of a protein-RNA interaction required for U6 snRNP formation, those at positions 47, 50, 52 and, to a lesser extent, position 51, produce more stable RNA and, where tested, appear to retain the ability to interact with U4 and U5 snRNPs. This result is consistent with that of Bindereif et al. (1990), who have demonstrated that a mutant human U6 RNA that contains a deletion of the first 52 nucleotides, which includes the invariant ACAGAG region, is efficiently assembled into U4/U6 particles in an in vitro system. Finally, we show here that a strain carrying the G50A mutation in U6 exhibits a significant decrease in the efficiency of the second step of the splicing reaction in vitro. Since the first step is efficiently completed, all previous steps of spliceosome assembly, including the destabilization of U4, must also occur.

\section{Possible implications}

As described in the introductory section, these studies were motivated by the hypothesis that U4 functions to deliver U6 to the spliceosome and to sequester functionally important residues in U6. Considering the simplest form of the hypothesis, one predicts the existence of residues in $\mathrm{U} 6$ that reside in the interaction domain that cannot be altered without abolishing their function; in contrast, their partners in U4 should be relatively insensitive to mutation, provided that the overall stability of the base-pairing interaction is maintained. Indeed this prediction is satisfied by the asymmetric phenotypes exhibited by the mutations in stem I described above. Second, as expected of residues whose (primary) function is in catalysis, most lethal mutants in U6 accumulate stable RNA and assemble into U4/U5/U6 snRNPs. Furthermore, one of these mutants, G50A, must be assembled into the spliceosome as it completes the first step of the splicing reaction in vitro.

Although the genetic and biochemical behavior of these mutants satisfy several important predictions of the hypothesis outlined above, we can by no means rule out the alternative interpretation that the essential residues identified by lethal point mutations function primarily as protein-binding sites. Genetic suppression studies may help to distinguish between these models. Ultimately, high-resolution structural studies will be required to determine whether these residues are part of the active site(s) of the spliceosome or whether they play a more indirect role.

It is, however, provocative to consider our results in the context of the discovery of mRNA-type introns in U6 snRNAs. On the basis of the identification of a single insertion event in stem I of $S$. pombe U6 (Tani and Oshima 19891, it was proposed that this region of U6 is in close proximity to the intron during the actual splicing reaction (Brow and Guthrie 1989). According to this view, residues in $\mathrm{U} 6$ flanking the intron insertion point are predicted to play a functionally important role in the reaction. We have shown that the AGC trinucleotide adjacent to the insertion site in stem I exhibits asymmetric behavior with respect to $\mathrm{U} 4$ and that mutations in these invariant residues must affect a step $(s)$ in the pathway downstream of formation of the triple snRNP. Although this correlation might have been argued to be purely coincidental, we now find a remarkable concordance with the location of a second intron in the conserved ACAGAG hexanucleotide in the yeast $R$. dacryoidum (T. Tani and Y. Oshima, pers. comm.). Taken together, these observations are consistent with the hypothesis that the nucleotides in stem I and the upstream hexanucleotide not only serve critical roles but are also good candidates for residues that participate directly in the splicing reaction.

\section{Materials and methods}

Yeast strains, plasmids, and genetic methods

The strain YHMI (MATa ura3 his3 lys2 trp1 leu2 snr6 :: LEU2 YCp50-SNR6) is a haploid strain carrying a disruption of the chromosomal copy of the SNR6 gene in which the U6-coding sequence (nucleotides -10 to +122 ; Brow and Guthrie 1988) is replaced by the yeast $L E U 2$ gene. The wild-type U6 gene is car- 
ried on a YCp50 (CEN, URA3) plasmid. The strain YKS2 (MATa ura3 his3 lys2 trp1 ade2 snr14 :: TRP1 YCp50-SNR14) was described previously (Bordonné et al. 1990). The shuttle vectors (pSE358, pSE360, and pSE362) used in this study were obtained from S. Elledge (Baylor University). pSE358 is a precursor of pUN10; pSE360 and pSE362 are identical to pUN50 and pUN90, respectively (Elledge and Davis 1988). All yeast manipulations were performed according to standard methods (Rose et al. 1989). The phenotypes of the U6 and U4 mutations were determined by the plasmid shuffle method (Boeke et al. 1987).

\section{Construction of a library of mutant SNR6 genes}

Introduction of restriction sites flanking the U6-coding sequence A 1.4-kb EcoRV-HpaI subclone containing the U6 gene (Brow and Guthrie 1988) was cloned into the EcoRV site of the pBluescript KS - vector (Stratagene). SphI and Xhol sites were introduced in the region flanking the coding sequence of SNR6 by oligonucleotide-directed mutagenesis using the Kunkel method (Kunkel et al. 1987; McClary et al. 1989). The SphI site was introduced at the $5^{\prime}$ end of the U6 gene by mutation of the nucleotides ACT (positions -7 to -5 ) to TGC. The Xhol site was created by making an A-to-C change at position +122 . This mutated DNA fragment was excised from the vector using the $B a m H I$ and Sall restriction sites present in the polylinker. BamHI linkers were added according to standard methods (Sambrook et al. 1989), and the resulting insert fragment was gel-purified. The yeast $-E$. coli shuttle vector pSE 358 (CEN, TRP1) was digested with SphI and BamHI, BamHI linkers were added, and the resulting DNA was gel-purified. Ligation of vector and insert resulted in the production of the plasmid pSX6. Yeast strains carrying this plasmid as sole source of U6 exhibited no growth defect compared to the parental strain, indicating that the EcoRV-Hpal genomic clone containing the SphI and XhoI sites could fully complement a disruption of SNR6.

Synthesis and cloning of the U6-coding sequence from degenerate oligonucleotides Two 82-nucleotide oligonucleotides were synthesized. Oligonucleotide 182 encodes the sense strand of SNR6 from nucleotides -13 to +69 (Brow and Guthrie 1988). Oligonucleotide 282 encodes the antisense strand of SNR6 from nucleotides +130 to +49 . The two oligonucleotides overlap by 21 nucleotides. They differ from the wild-type sequence in that oligonucleotide 182 carries an SphI site at its $5^{\prime}$ end and oligonucleotide 282 contains an Xhol site at its $3^{\prime}$ end; these sites are identical to those introduced above. Both oligonucleotides were synthesized at a low level of degeneracy $199.84 \%$ correct, $0.16 \%$ mixture of the three incorrect nucleotides) throughout their length. The oligonucleotides were annealed by heating to $75^{\circ} \mathrm{C}$ and cooling slowly $\left(1^{\circ} \mathrm{C} / \mathrm{min}\right)$ to room temperature in a $0.5-\mathrm{ml}$ mixture containing $10 \mathrm{mM}$ Tris$\mathrm{HCl}(\mathrm{pH} 7.5), 50 \mathrm{~mm} \mathrm{NaCl}, 10 \mathrm{~mm} \mathrm{MgCl}_{2}, 5 \mathrm{~mm}$ DTT, 33 $\mathrm{mg} / \mathrm{ml} \mathrm{BSA}$, and $400 \mathrm{ng}$ of each oligonucleotide. Following annealing, dATP, dCTP, dGTP, and dTTP were added to a final concentration of $250 \mu \mathrm{M}$ along with 300 units of the Klenow fragment of $E$. coli DNA polymerase I in a final reaction volume of $0.6 \mathrm{ml}$. Following incubation at $23^{\circ} \mathrm{C}$ for $1 \mathrm{hr}$, the mixture was extracted with phenol and choloform, precipitated with ethanol, and digested with 300 units of SphI and 600 units of Xhol in a volume of $0.1 \mathrm{ml}$. The reaction mixture was then extracted with phenol and chloroform, precipitated with ethanol, resuspended in $10 \mathrm{mM}$ Tris- $\mathrm{HCl}(\mathrm{pH} 8.0)$, and $1 \mathrm{~mm}$ EDTA, and chromatographed on Sephadex G-50 to remove the short end oligonucleotides created by restriction digestion. The flowthrough fraction represents a pool of degenerate DNA fragments that correspond to the coding sequence of the U6 gene.

The plasmid pSX6 $(1 \mu \mathrm{g})$ described above was digested with SphI and Xhol. The large fragment lacking the SNR6-coding sequence was gel-purified and ligated to the pool of degenerate U6 DNA fragments described above using T4 DNA ligase. The reaction mixture was treated with Geneclean (Bio 101) according to the manufacturer's recommendations, and the DNA was introduced into the E. coli strain DH5a (Hanahan 1983) by electroporation (Dower et al. 1988). We made the assumption that the twofold higher level of degeneracy in the region where the two oligonucleotides overlap is corrected by mismatch repair in E. coli. We have detected no bias either for or against mutations in the overlap region (see Table 1). A small amount of the transformation mixture was plated in serial dilutions to assess transformation efficiency; the rest was used to inoculate a 1 liter culture for the preparation of plasmid DNA. The serial dilutions revealed that there were $\sim 2 \times 10^{5}$ transformants.

Expected and observed frequencies of single nucleotide substitutions The expected fraction of mutants in the library containing a single-nucleotide substitution was calculated using the formula $F(P)=n ! P^{n-r}(1-P)^{r} /(n-r) ! r$ !, where $F(P)$ is the fraction of oligonucleotides that contain $r$ changes in a sequence of length $n$, and $1-P$ is the level of degeneracy /Sambrook et al. 1989). In our case, considering single changes $|r=1|$ in the SNR6-coding sequence $(n=112)$, where the level of degeneracy is 0.0016 , the fraction of molecules containing a single change is equal to 0.15 . Sequencing of 43 randomly selected clones from the mutant library revealed six $(14 \%)$ that contained a single change in the SNR6-coding region, in reasonable agreement with the $15 \%$ value predicted (data not shown). Since there are $336(112 \times 3)$ possible single-nucleotide substitutions in SNR6, each mutation will be represented once, on average, in 2240 clones $(336 / 0.15)$. Therefore, by screening 5000 colonies, each single-nucleotide substitution would be expected to be represented 2.2 times on average. Again, this is approximately equal to the observed value of 2.0 /calculated from values listed in Table 11 .

\section{Isolation and analysis of mutant plasmids}

Plasmid DNAs were isolated from yeast using the glass bead/ phenol method (Hoffman and Winston 1987), treated with Geneclean, and introduced into $E$. coli by electroporation (Dower et al. 1988). Mutant plasmids were digested with SphI and Xhol and fractionated on $2 \%$ agarose gels. Those that contained inserts that were approximately the same size as wild type were analyzed further. The coding-region sequence of the U6 mutants was determined by dideoxynucleotide sequencing using Sequenase (U.S. Biochemicals). The phenotype of each mutant was confirmed using the plasmid shuffle assay as described above.

\section{Site-directed mutagenesis of SNR6 and SNR14}

Oligonucleotide-directed mutagenesis of the 5' stem-loop and the ACAGAGA regions of the U6 gene and of stem I of both U4 and $\mathrm{U} 6$ was performed using the Kunkel method (Kunkel et al. 1987; McClary et al. 1989/. By using two degenerate oligonucleotides, we obtained 12 multiple mutants and 15 single-point substitutions in the ACAGAGA motif of the U6 gene. Five other mutants of this region were a generous gift from Patrizia Fabrizio (California Institute of Technology). The U6 mutants were subcloned into pSE358, and the U4 mutants were subcloned into pSE362. 
Northern hybridization, velocity sedimentation analysis, and in vitro splicing

Total yeast RNA was prepared using the guanidinium thiocyanate method (Wise et al. 1983). Electrophoresis, transfer and hybridization conditions, as well as glycerol gradient analysis, were performed as described previously (Bordonné et al. 1990). Yeast whole-cell extract preparation, synthesis of actin precursor, and in vitro splicing conditions were performed according to Lin et al. (1985).

\section{Acknowledgments}

We gratefully acknowledge Karen Shannon who generated and analyzed several stem I mutants as well as the U4 deletion strain used in this study. Whole-cell extract for performing in vitro transcription assays was kindly provided by David Brow, and fraction I was a gift from Beate Schwer. We thank Patrizia Fabrizio and John Abelson for exchanging ACAGAGA box mutants and freely discussing unpublished results. We also thank Ian Mattaj and Albrecht Bindereif for helpful discussions. Paul Bates provided invaluable advice on gene synthesis and library construction. We are also indebted to members of the laboratory for lively discussion and helpful comments on the manuscript. Lucita Esperas provided excellent technical assistance. H.D.M. is a trainee of the Medical Scientist Training Program. R.B. was supported by grants from the Centre National de la Recherche Scientifique and the Philippe Foundation. This work was supported by a grant to C.G. from the National Institutes of Health (GM21119).

The publication costs of this article were defrayed in part by payment of page charges. This article must therefore be hereby marked "advertisement" in accordance with 18 USC section 1734 solely to indicate this fact.

\section{References}

Bindereif, A. and M.R. Green. 1987. An ordered pathway of snRNP binding during mammalian pre-mRNA splicing complex assembly. EMBO /. 6: 2415-2424.

Bindereif, A., T. Wolff, and M.R. Green. 1990. Discrete domains of human U6 snRNA required for the assembly of U4/U6 snRNP and splicing complexes. EMBO J. 9: 251-255.

Black, D.L., B. Chabot, and J.A. Steitz. 1985. U2 as well as U1 small ribonucleoprotein particles are involved in pre-mRNA splicing. Cell 42: 737-750.

Blencowe, B.J., B.S. Sproat, U. Ryder, S. Barabino, and A.I. Lamond. 1989. Antisense probing of the human U4/U6 snRNP with biotinylated 2'-OMe RNA oligonucleotides. Cell 59: $531-539$.

Boeke, J. D., J. Truehart, G. Natsoulis, and G.R. Fink. 1987. 5Fluoroorotic acid as a selective agent in yeast molecular genetics. Methods Enzymol. 154: 164-175.

Bordonné, R., J. Banroques, I. Abelson, and C. Guthrie. 1990. Domains of yeast U4 spliceosomal RNA required for PRP4 binding, snRNP-snRNP interactions, and pre-mRNA splicing in vivo. Genes Dev. 4: 1185-1196.

Bringmann, P., B. Appel, J. Rinke, R. Reuter, H. Theissen, and R. Lührmann. 1984. Evidence of the existence of snRNAs $\mathrm{U} 4$ and $\mathrm{U} 6$ in a single ribonucleoprotein complex and for their association by intermolecular base pairing. EMBO $\%$. 3: $1357-1363$.

Brow, D.A. and C. Guthrie. 1988. Spliceosomal RNA U6 is remarkably conserved from yeast to mammals. Nature 334: $213-218$.

- 1989. Splicing a spliceosomal RNA. Nature 337: 14-15.
1990. Transcription of a yeast U6 snRNA gene requires a polymerase III promoter element in a novel position. Genes Dev. 4: 1345-1356.

Cech, T.R. 1986. The generality of self-splicing RNA, relationship to nuclear mRNA splicing. Cell 44: 207-210.

Cheng, S.-C. and J. Abelson. 1986. Fractionation and characterization of a yeast mRNA splicing extract. Proc. Natl. Acad. Sci. 83: 2387-2391.

1987. Spliceosome assembly in yeast. Genes Dev. 1: $1014-1027$.

Dower, W.I., I.F. Miller, and C.W. Ragsdale. 1988. High efficiency transformation of $\mathrm{E}$. coli by high voltage electroporation. Nucleic Acids Res. 16: 6127-6145.

Elledge, S.J. and R.W. Davis. 1988. A family of versatile centromeric vectors for use in the sectoring-shuffle mutagenesis assay in Saccharomyces cerevisiae. Gene 70: 303-312.

Guthrie, C. and B. Patterson. 1988. Spliceosomal snRNAs. Annu. Rev. Gen. 23: 387-419.

Hamm, J. and I.W. Mattaj. 1989. An abundant U6 snRNP found in germ cells and embryos of Xenopus laevis. EMBO $\%$. 8: $4179-4187$.

Hanahan, D. 1983. Studies on the transformation of Escherichia coli with plasmids. J. Mol. Biol. 166: 557

Hashimoto, C. and J.A. Steitz. 1984. U4 and U6 RNAs coexist in a single small nuclear ribonucleoprotein particle. Nucleic Acids Res. 12: 3283-3293.

Hoffman, C.S. and F. Winston. 1987. A ten-minute DNA preparation from yeast efficiently releases autonomous plasmids for transformation of Escherichia coli. Gene 57: 267-272.

Igel, A.H. and M. Ares, Jr. 1988. Internal sequences that distinguish yeast from metazoan U2 snRNA are unnecessary for pre-mRNA splicing. Nature 334: 450-453.

Jones, M.H. and C. Guthrie. 1990. Unexpected flexibility in an evolutionarily conserved protein-RNA interaction: Genetic analysis of the Sm binding site. EMBO /. 9: 2555-2561.

Konarska, M.M. and P.A. Sharp. 1987. Interactions between small nuclear ribonucleoprotein particles in formation of spliceosomes. Cell 49: 763-774.

- 1988. Association of U2, U4, U5, and U6 small nuclear ribonucleoproteins in a spliceosome-type complex in absence of precursor RNA. Proc. Nat1. Acad. Sci.. 85: 54595462 .

Kretzner, L., A. Krol, and M. Rosbash. 1990. Saccharomyces cerevisiae Ul small nuclear RNA secondary structure contains both universal and yeast-specific domains. Proc. Natl. Acad. Sci. 87: 851-855.

Krol, A., P. Carbon, I.P. Ebel, and B. Appel. 1987. Xenopus tropicalis U6 snRNA genes transcribed by Pol III contain the upstream promoter elements used by Pol II dependent U snRNA genes. Nucleic Acids Res. 15: 2463-2478.

Kunkel, G.R., R.L. Maser, J.P. Calvet, and T. Pederson. 1986. U6 small nuclear RNA is transcribed by RNA polymerase III. Proc. Natl. Acad. Sci. 83: 8575-8579.

Kunkel, T.A., J.D. Roberts, and R.A. Zakour. 1987. Rapid and efficient site-specific mutagenesis without phenotypic selection. Methods Enzymol. 154: 367-382.

Lamond, A.I., M.M. Konarska, P.J. Grabowski, and P.A. Sharp. 1988. Spliceosome assembly involves the binding and release of U4 small nuclear ribonucleoprotein. Proc. Natl. Acad. Sci. 85: 411-415.

Lin, R.J., A.J. Newman, S.-C. Cheng, and J. Abelson. 1985. Yeast mRNA splicing in vitro. I. Biol. Chem. 260: 14780-14792.

Lührmann, R. 1988. snRNP proteins. In Structure and function of maior and minor small nuclear ribonucleoprotein particles (ed. M.L. Birnstiel), pp. 71-99. Springer-Verlag/Berlin.

Maniatis, T. and R. Reed. 1987. The role of small nuclear ribo- 
nucleoprotein particles in pre-mRNA splicing. Nature 325: 673-678.

Mattaj, I.W., N.A. Dathan, H.D. Parry, P. Carbon, and A. Krol. 1988. Changing the RNA polymerase specificity of $U$ snRNA gene promoters. Cell 55: 435-442.

McClary, J.A., F. Witney, and J. Geisselsoder. 1989. Efficient site-directed in vitro mutagenesis using phagemid vectors. Biotechniques 3: 282-289.

McPheeters, D.S., P. Fabrizio, and J. Abelson. 1989. In vitro reconstitution of functional yeast U2 snRNPs. Genes Dev. 3: 2124-2136.

Mount, S.M., I. Petterson, M. Hinterberger, A. Karmas, and J.A. Steitz. 1983. The U1 small nuclear RNA-protein complex selectively binds a 5' splice site in vitro. Cell 33: 509-518.

Parker, R., P.G. Siliciano, and C. Guthrie. 1987. Recognition of the TACTAAC box during mRNA splicing in yeast involves base pairing to the U2-like snRNA. Cell 49: 229-239.

Pikielny, C.W., B.C. Rymond, and M. Rosbash. 1986. Electrophoresis of ribonucleoproteins reveals an ordered assembly pathway of yeast splicing complexes. Nature 324: $341-345$.

Reddy, R., D. Henning, G. Das, M. Marless, and D. Wright. 1987. The capped U6 small nuclear RNA is transcribed by RNA polymerase III. $J$. Biol. Chem. 262: 75-81.

Rinke, J., B. Appel, M. Digweed, and R. Lührmann 1985. Localization of a base-paired interaction between small nuclear RNAs U4 and U6 in intact U4/U6 ribonucleoprotein particles by psoralen cross-linking. 1. Mol. Biol. 185: 721-731.

Roiha, H., E.O. Shuster, D.A. Brow, and C. Guthrie. 1989. Small nuclear RNAs from budding yeasts; phylogenetic comparisons reveal extensive size variation. Gene 82: 137-144.

Rose, M.D., F. Winston, and P. Hieter. 1989. Methods in yeast genetics. Cold Spring Harbor Laboratory Press, Cold Spring Harbor, New York.

Sambrook, J., E.F. Fritsch, and T. Maniatis. 1989. Molecular cloning: A laboratory manual, 2nd ed. Cold Spring Harbor Laboratory Press, Cold Spring Harbor, New York.

Séraphin, B., L. Kretzner, and M. Rosbash. 1988. A Ul snRNA : pre-mRNA base pairing interaction is required early in yeast spliceosome assembly but does not uniquely define the $5^{\prime}$ cleavage site. EMBO /. 7: 2533-2538.

Sharp, P.A. 1985. On the origins of RNA splicing and introns. Cell 42: 397-400.

___ 1987. Splicing messenger RNA precursors. Science 235: 766-771.

Shuster, E.O. and C. Guthrie. 1988. Two conserved domains of yeast U2 snRNA are separated by 945 nonessential nucleotides. Cell 55: 41-48.

- 1990. Human U2 snRNA can function in pre-mRNA splicing in yeast. Nature 345: 270-273.

Siliciano, P.G. and C. Guthrie. 1988. $5^{\prime}$ Splice site selection in yeast: Genetic alterations in base-pairing with $U 1$ reveal additional requirements. Genes Dev. 2: 1258-1267.

Siliciano, P.G., D.A. Brow, H. Roiha, and C. Guthrie. 1987. An essential snRNA from $S$. cerevisiae has properties predicted for U4, including interaction with a U6-like snRNA. Cell 50: $585-592$.

Steitz, J.A., D.L. Black, V. Gerke, K.A. Parker, A. Kramer, D. Frendewey, and W. Keller. 1988. Functions of the abundant U-snRNPs. In Structure and function of major and minor small nuclear ribonucleoprotein particles (ed. M.L. Birnstiel), pp. 115-154. Springer-Verlag, Berlin.

Tani, T. and Y. Ohshima. 1989. The gene for the U6 small nuclear RNA in fission yeast has an intron. Nature 337: $87-$ 90.

Wise, J.A., D. Tollervey, D. Maloney, H. Swerdlow, E.J. Dunn, and C. Guthrie. 1983. Yeast contains small nuclear RNAs encoded by single copy genes. Cell 35: 743-751.

$\mathrm{Wu}, \mathrm{J}$. and J.L. Manley. 1989. Mammalian pre-mRNA branch site selection by U2 snRNP involves base pairing. Genes Dev. 3: $1553-1561$.

Xu, Y., S. Petersen-Bjoørn, and J.D. Friesen. 1990. The PRP4 (RNA4) protein of Saccharomyces cerevisiae is associated with the $5^{\prime}$ portion of the U4 small nuclear RNA. Mol. Cell. Biol. 10: 1217-1225.

Zhuang, Y. and A.M. Weiner. 1986. A compensatory base change in Ul snRNA suppresses a $5^{\prime}$ splice site mutation. Cell 46: $827-835$.

1989. A compensatory base change in human U2 snRNA can suppress a branch site mutation. Genes Dev. 3: $1545-1552$. 


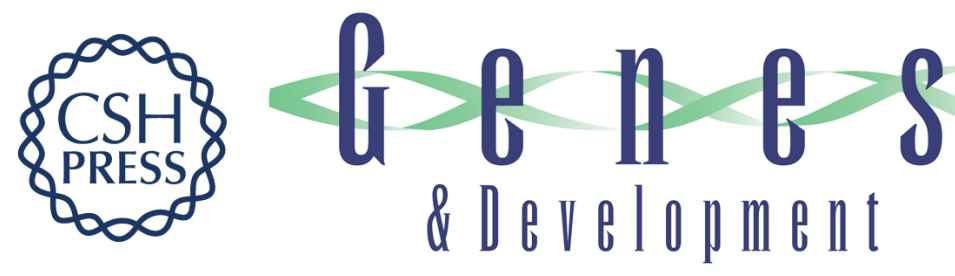

\section{Multiple roles for U6 snRNA in the splicing pathway.}

H D Madhani, R Bordonné and C Guthrie

Genes Dev. 1990, 4:

Access the most recent version at doi:10.1101/gad.4.12b.2264

References This article cites 53 articles, 16 of which can be accessed free at: http://genesdev.cshlp.org/content/4/12b/2264.full.html\#ref-list-1

License

Email Alerting Receive free email alerts when new articles cite this article - sign up in the box at the top Service right corner of the article or click here.

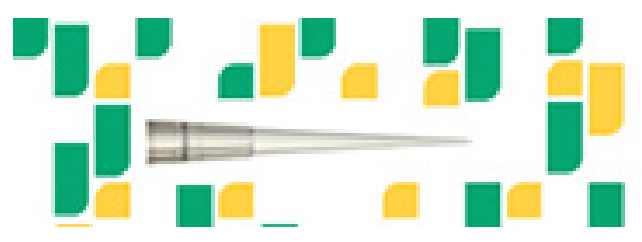

Focused on your science. 